\title{
Pulmonary resection is associated with long-term survival and should remain a therapeutic option in oligometastatic lung cancer
}

Kyle G. Mitchell, MD, ${ }^{\mathrm{a}}$ Ahsan Farooqi, MD, PhD, ${ }^{\mathrm{b}}$ Ethan B. Ludmir, MD, ${ }^{\mathrm{b}}$ Erin M. Corsini, MD, ${ }^{\mathrm{a}}$ Boris Sepesi, MD, ${ }^{a}$ Daniel R. Gomez, MD, ${ }^{b}$ and Mara B. Antonoff, MD, ${ }^{a}$ the MD Anderson Cancer Center Oligometastatic Lung Cancer Working Group*

\section{ABSTRACT}

Objectives: Comprehensive local consolidative therapy led to improved overall survival in oligometastatic non-small cell lung cancer in a recent phase II trial, yet the role of pulmonary resection in ongoing oligometastatic trials is a matter of controversy. We sought to examine outcomes after pulmonary resection with radiotherapy used as a benchmark comparator.

Methods: Patients treated at a single institution (2000-2017) with cT1-3No-2M1 non-small cell lung cancer, 3 or less synchronous metastases, and performance status 0 to 1 , and who received comprehensive local consolidative therapy were analyzed according to local consolidative therapy modality for the primary lesion. Progression was analyzed with death as a competing risk.

Results: Of 88 patients meeting inclusion criteria, $63(71.6 \%)$ received radiotherapy for local consolidative therapy modality for the primary lesion and $25(28.4 \%)$ underwent surgery (lobectomy 20/25 [80.0\%], pneumonectomy 3/25 [12.0\%], sublobar $2 / 25[8.0 \%])$. Time from diagnosis to local consolidative therapy modality for the primary lesion was similar. Surgical patients were younger and had lower intrathoracic disease burden. Ninety-day post-treatment mortality was low (surgery $0 / 25$ $[0.0 \%]$, radiotherapy $1 / 63[1.6 \%]$ ). Median postoperative survival time was 55.2 months ( $95 \%$ confidence interval, 20.1 to not reached), with 1- and 5-year overall survivals of $95.7 \%$ and $48.0 \%$, respectively. After radiotherapy, median postoperative survival time was 23.4 months (confidence interval, 17.2-35.9); 1- and 5-year overall survivals were $74.3 \%$ and $24.2 \%$, respectively. No differences were observed between modalities in site of first failure, cumulative incidence of locoregional failure $(P=.635)$, or systemic progression $(P=.747)$.

Conclusions: Pulmonary resection is feasible and associated with long-term survival in selected patients with synchronous oligometastatic non-small cell lung cancer. Surgery should remain a local consolidative therapeutic option for patients with operable oligometastatic non-small cell lung cancer enrolled in ongoing and future randomized clinical trials. ( $J$ Thorac Cardiovasc Surg 2021;161:1497-504)

Although the prognosis for patients with metastatic nonsmall cell lung cancer (NSCLC) historically has been limited, ${ }^{1}$ we and others have demonstrated improved

\footnotetext{
From the Departments of ${ }^{a}$ Thoracic and Cardiovascular Surgery, and ${ }^{\mathrm{b}}$ Radiation Oncology, The University of Texas MD Anderson Cancer Center, Houston, Tex. Read at the 2019 AATS International Thoracic Surgical Oncology Summit.

* MD Anderson Cancer Center Oligometastatic Lung Cancer Working Group: Ara A. Vaporciyan, MD, Stephen G. Swisher, MD, John V. Heymach, MD, PhD, Jianjun Zhang, MD, PhD, Saumil J. Gandhi, MD, PhD.

Received for publication Sept 22, 2019; revisions received Feb 7, 2020; accepted for publication Feb 8, 2020; available ahead of print March 25, 2020.
}

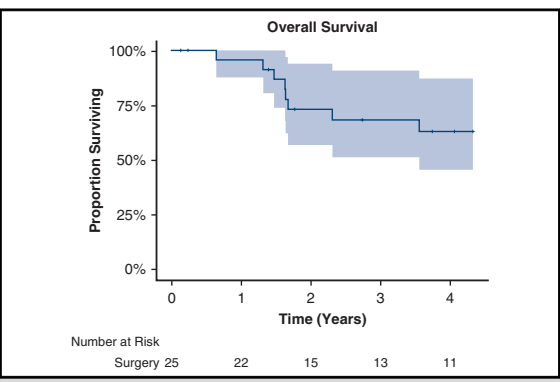

Pulmonary resection is associated with durable OS in oligometastatic NSCLC.

\section{CENTRAL MESSAGE}

As indications for local consolidate therapy in oligometastatic NSCLC expand, pulmonary resection should remain a therapeutic option for patients in clinical practice and in randomized trials.

\section{PERSPECTIVE}

Primary tumor resection is associated with longterm survival in a selected group of patients with synchronous oligometastatic NSCLC. The lack of clear differences between surgery and radiotherapy in terms of locoregional and systemic control highlight that both modalities should remain local therapeutic options for patients with oligometastatic NSCLC as additional prospective data accrue.

See Commentaries on pages 1505,1507 , and 1508. 


$$
\begin{aligned}
& \text { Abbreviations and Acronyms } \\
& \begin{aligned}
\text { BED } & =\text { biologically equivalent dose } \\
\text { ICI } & =\text { immune checkpoint inhibitor } \\
\text { LCT } & =\text { local consolidative therapy } \\
\text { NSCLC } & =\text { non-small cell lung cancer } \\
\text { OS } & =\text { overall survival } \\
\text { SSS } & =\text { Surgical Selection Score }
\end{aligned}
\end{aligned}
$$

Scanning this QR code will take you to the table of contents to access supplementary information. To view the AATS Annual Meeting Webcast, see the URL next to the webcast thumbnail.

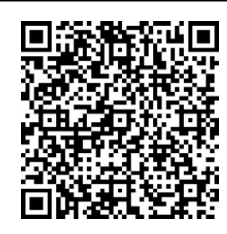

sites of disease when compared with maintenance therapy or observation. ${ }^{2,3}$ A recent phase II trial reported improved OS after administration of stereotactic body radiotherapy (SBRT) to all disease sites among a cohort of patients with oligometastatic cancers. ${ }^{4}$ Given these results, interest in use of radiotherapy, surgical therapy, and other local ablative modalities in the setting of oligometastatic NSCLC is rapidly expanding (NCT03391869, NCT03707938, NCT03137771, NCT02417662, NCT03410043). ${ }^{5}$

However, concerns regarding the advisability of maximally aggressive local therapy in the context of stage IV disease persist, and whether surgical therapy should remain a therapeutic option for management of the primary lesion in ongoing and future clinical trials is a matter of debate. We sought to characterize post-therapeutic outcomes among patients with oligometastatic NSCLC who underwent pulmonary resection in the context of a cohort of patients treated with radiotherapy as a benchmark group. Moreover, given the paucity of data regarding the modality better suited to optimize disease control in the oligometastatic setting, we further aimed to explore patterns of treatment failure after each modality of $\mathrm{LCT}_{\text {Primary }}$. We hypothesized that, among a highly selected cohort, pulmonary resection would be associated with durable OS and locoregional control.

\section{MATERIALS AND METHODS \\ Patient Population}

Patients presenting to the University of Texas MD Anderson Cancer Center between 2000 and 2017 with stage IV NSCLC and 3 or less synchronous metastases were eligible for inclusion. Cases were identified using natural language processing algorithms that searched medical records for strings related to oligometastatic disease ("oligomet*," "limited met*," "isolated met*," "single met*," "solitary met*"); these records were then manually reviewed to determine eligibility. ${ }^{6}$ The number of metastatic sites was defined in a fashion concordant with recent publications ${ }^{2,7}$ : intrathoracic nodal disease was counted as 1 site (regardless of the number or location of nodes involved), and multiple metastatic lesions within a single organ were counted as discrete sites. Synchronous primary lung metastases were distinguished from pulmonary metastases according to the criteria of Martini and Melamed ${ }^{8}$ and genomic profiling of individual pulmonary lesions when such data were available. Only patients who received comprehensive LCT, that is, local therapy to all disease sites, were included. To restrict this analysis to patients who could be considered medically operable with resectable primary lesions, patients who had cT1-3N02M1 disease and Eastern Cooperative Oncology Group performance status 0-1 were included (Figure 1). We excluded patients with cT4 and/or cN3 disease to limit to a group that would typically be considered resectable in clinical practice. All patients underwent complete staging in accordance with national guidelines in effect at the time of diagnosis; we permitted patients who did not undergo invasive mediastinal staging, because this is not a current clinical standard for patients with M1 disease. ${ }^{9}$ At our institution, if dose constraints are met we attempt modest radiotherapy dose escalation to the primary tumor to a total biologically equivalent dose (BED) of 5560 Gray (calculated assuming alpha/beta ratio 10.0); we therefore excluded patients who underwent radiotherapy as $\mathrm{LCT}_{\text {Primary }}$ and received BED less than 55 Gray. No restrictions were placed with respect to receipt or timing of systemic therapy in relation to local therapies. A subset of the patients included in this cohort were enrolled in a phase II randomized controlled trial, ${ }^{2}$ and the present study represents a subgroup analysis of another work. ${ }^{6}$ All tumors were retrospectively staged according to the 8th edition of the American Joint Committee on Cancer's staging guidelines. ${ }^{10}$ This study was approved by MD Anderson's Institutional Review Board with a waiver of informed patient consent.

\section{Outcome Definitions and Statistical Analysis}

All patients considered for comprehensive LCT were evaluated in a multidisciplinary setting, and decisions regarding the modality and sequence of therapies were made on an individualized basis. Therefore, given the inherent selection biases and suspected presence of unmeasured confounders for which we could not appropriately account in a retrospective manner, no direct comparisons of OS outcomes were made between $\mathrm{LCT}_{\text {Primary }}$ subgroups. The Surgical Selection Score (SSS) is a composite risk-stratification measure that predicted OS among patients with advanced NSCLC in population-level analyses and is composed of patient and tumor characteristics (including age, comorbidity index, race, histology, tumor burden, and type of treating facility, insurance, and income). ${ }^{11,12}$ To account for selection biases with regard to $\mathrm{LCT}_{\text {Primary }}$ modality and differences in baseline clinicopathologic characteristics between groups, exploratory analyses (among patients with SSS greater than the observed median for the cohort) were performed after stratification according to the continuous, composite SSS index. The SSS was chosen for stratification given its previously demonstrated prognostic significance ${ }^{11}$ and its ability to discriminate patients chosen for surgical therapy. ${ }^{12}$ These exploratory stratified analyses were performed in an effort to exclude patients whose were predicted by an objective criterion to have poor prognosis and to be unlikely to be selected for surgical therapy. Because all patients in this cohort were treated at a single institution and patient income data were not accessible for this study, patient income level was not included in calculation of the score; insurance provider was also deliberately excluded from calculation of the SSS.

Categoric variables were analyzed using Pearson's chi-square and Fisher exact tests as appropriate, and continuous variables were analyzed using the Mann-Whitney $U$ and Kruskal-Wallis tests. To limit the bias on survival estimates of potentially different intervals of time between groups from the time of diagnosis to $\mathrm{LCT}_{\text {Primary }}$, OS was a priori defined as the time from $\mathrm{LCT}_{\text {Primary }}$ until death from any cause. Patients alive at the end of the study period were censored at the time of last follow-up. Locoregional progression was defined as disease progression at treated primary tumor or regional nodes, and systemic progression was defined the development of new systemic metastases. Survival times were estimated using the Kaplan-Meier method and differences in time-to-event outcomes 


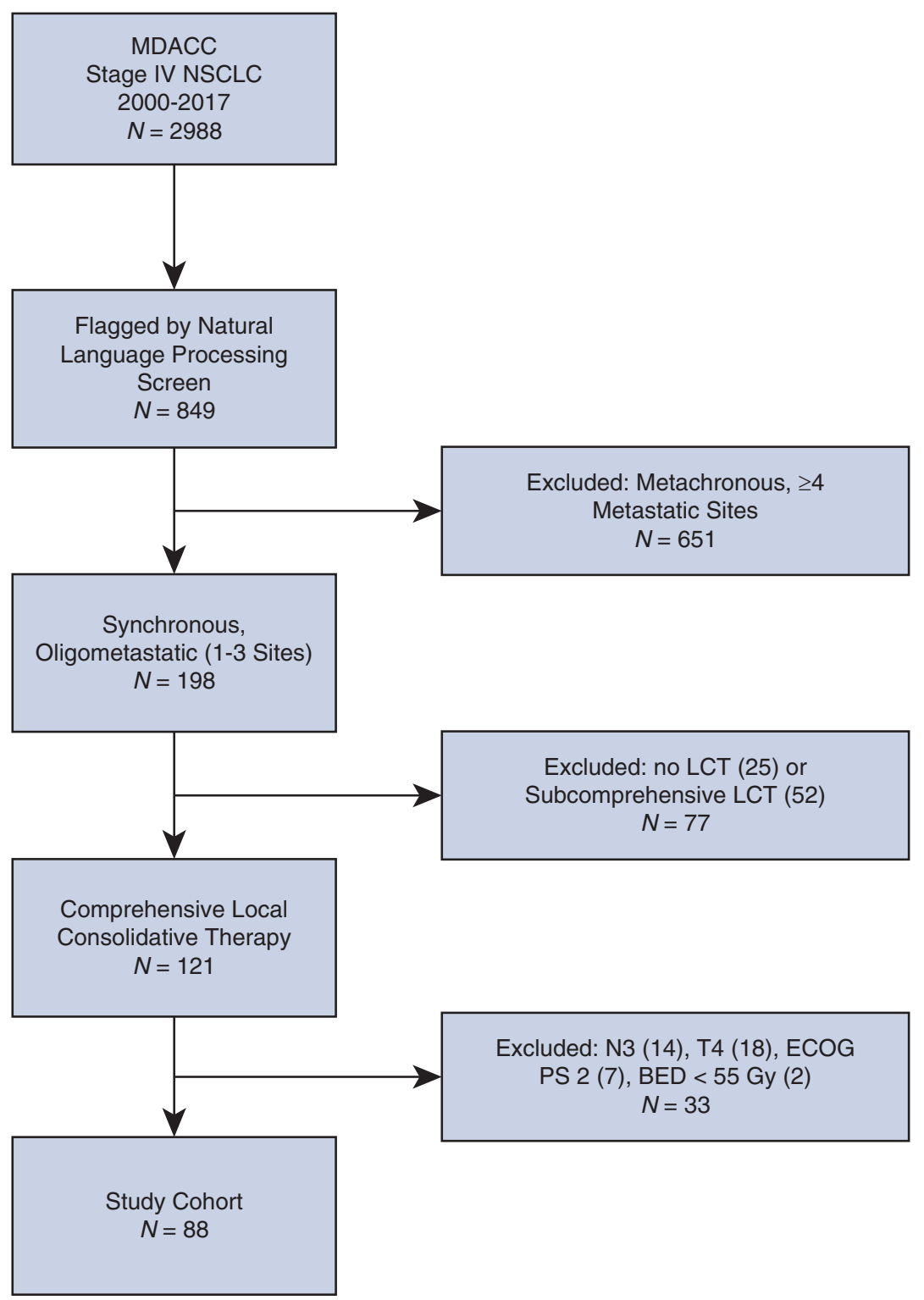

FIGURE 1. Consolidated Standards of Reporting Trials diagram. Comprehensive LCT was defined as local therapy directed at the primary tumor and all sites of metastatic disease; subcomprehensive LCT was defined as LCT to some, but not all, sites of disease. MDACC, MD Anderson Cancer Center; NSCLC, non-small cell lung cancer; $L C T$, local consolidative therapy; ECOG, Eastern Cooperative Oncology Group; $P S$, performance status; $B E D$, Biologically equivalent dose.

between groups were analyzed using the log-rank test. The reversed Kaplan-Meier method was used to estimate median follow-up duration. ${ }^{13}$ Competing risks analyses were performed with death as a competing risk for locoregional and systemic progression events. All analyses were performed using R (packages cmprsk, survminer) (R Foundation for Statistical Computing, Vienna, Austria; http://r-project.org) and Stata (version 15.1; StataCorp LP, College Station, Tex).

\section{RESULTS}

\section{Cohort Characteristics}

Of 88 patients who met inclusion criteria, 63 (71.6\%) underwent radiotherapy and $25(28.4 \%)$ underwent pulmonary resection as $\mathrm{LCT}_{\text {Primary }}$ (Table 1). Most patients (57,
$64.8 \%)$ had 2 to 3 sites of metastases; brain $(47 / 88$, $53.4 \%)$, bone $(23,26.1 \%)$, and adrenal $(10,11.4 \%)$ were the most common sites of metastatic lesions at the time of presentation. Patients who underwent resection of their primary tumor were younger and had a lower intrathoracic disease burden than those who underwent radiotherapy (Table 1). No difference was observed in the frequency of known driver mutations between groups (radiotherapy: 17/63, 27.0\%; surgery: $7 / 25,28.0 \% ; P=.923)$. Systemic therapy was administered at similar rates in both groups (radiotherapy: 58/63, 92.1\%; surgery: 20/25, 80.0\%; $P=.139)$. Of patients who received systemic therapy, a 
TABLE 1. Baseline clinical, tumor, and treatment characteristics of the study cohort $(\mathbf{N}=\mathbf{8 8})$

\begin{tabular}{|c|c|c|c|}
\hline Variable & $\begin{array}{l}\text { Radiotherapy } \\
\qquad(N=63)\end{array}$ & $\begin{array}{l}\text { Surgery } \\
(\mathbf{N}=\mathbf{2 5})\end{array}$ & $P$ \\
\hline Age, y & $63.6(54.0-72.0)$ & $58.2(54.0-64.0)$ & .070 \\
\hline $\begin{array}{l}\text { Sex } \\
\quad \text { Female } \\
\quad \text { Male }\end{array}$ & $\begin{array}{l}25(39.7) \\
38(60.3)\end{array}$ & $\begin{array}{l}12(48.0) \\
13(52.0)\end{array}$ & .476 \\
\hline $\begin{array}{l}\text { Smoking status } \\
\text { Never } \\
\text { Former/current }\end{array}$ & $\begin{array}{r}8(12.7) \\
55(87.3)\end{array}$ & $\begin{array}{r}6(24.0) \\
19(76.0)\end{array}$ & .208 \\
\hline $\begin{array}{l}\text { Race } \\
\text { NHW } \\
\text { NHB } \\
\text { Other }\end{array}$ & $\begin{array}{c}56(88.9) \\
4(6.4) \\
1(4.8)\end{array}$ & $\begin{array}{c}22(88.0) \\
1(4.0) \\
2(8.0)\end{array}$ & .857 \\
\hline $\begin{array}{c}\text { ECOG PS } \\
0 \\
1\end{array}$ & $\begin{array}{l}23(36.5) \\
40(63.5)\end{array}$ & $\begin{array}{l}14(56.0) \\
11(44.0)\end{array}$ & .095 \\
\hline $\begin{array}{l}\text { Charlson-Deyo } \\
\text { Comorbidity Index } \\
0 \\
1 \\
2\end{array}$ & $\begin{array}{c}44(69.8) \\
13(20.6) \\
6(9.5)\end{array}$ & $\begin{array}{r}18(72.0) \\
4(16.0) \\
3(12.0)\end{array}$ & .868 \\
\hline $\begin{array}{l}\text { Histology } \\
\text { Nonsquamous } \\
\text { Squamous cell } \\
\text { carcinoma }\end{array}$ & $\begin{array}{l}50(79.4) \\
13(20.6)\end{array}$ & $\begin{array}{c}23(92.0) \\
2(8.0)\end{array}$ & .215 \\
\hline $\begin{array}{l}\text { Mutation } \\
\text { EGFR } \\
\text { KRAS } \\
\text { TP53 } \\
\text { STK11/LKB1 } \\
\text { ROS1 } \\
\text { ALK }\end{array}$ & $\begin{aligned} 8 & (12.7) \\
8 & (12.7) \\
12 & (19.1) \\
3 & (4.8) \\
0 & (0.0) \\
0 & (0.0)\end{aligned}$ & $\begin{array}{l}5(20.0) \\
3(12.0) \\
2(8.0) \\
2(8.0) \\
0(0.0) \\
0(0.0)\end{array}$ & $\begin{array}{l}.506 \\
1.000 \\
.333 \\
.620 \\
- \\
-\end{array}$ \\
\hline Tumor size, cm (IQR) & $3.7(2.9-5.0)$ & $2.8(2.2-3.5)$ & .017 \\
\hline $\begin{array}{l}\mathrm{T} \\
1 \\
2 \\
3\end{array}$ & $\begin{array}{l}15(23.8) \\
30(47.6) \\
18(28.6)\end{array}$ & $\begin{array}{r}13(52.0) \\
9(36.0) \\
3(12.0)\end{array}$ & .029 \\
\hline $\begin{array}{r}\mathrm{N} \\
0 \\
1 \\
2\end{array}$ & $\begin{array}{l}22(34.9) \\
10(15.9) \\
31(49.2)\end{array}$ & $\begin{array}{r}16(64.0) \\
5(20.0) \\
4(16.0)\end{array}$ & .010 \\
\hline $\begin{array}{l}\text { No. of metastatic sites } \\
1 \\
2 \\
3\end{array}$ & $\begin{array}{l}17(27.0) \\
34(54.0) \\
12(19.1)\end{array}$ & $\begin{array}{c}14(56.0) \\
9(36.0) \\
2(8.0)\end{array}$ & .041 \\
\hline $\begin{array}{l}\text { Location of metastases } \\
\text { Brain } \\
\text { Bone } \\
\text { Adrenal } \\
\text { Liver } \\
\text { Lung }\end{array}$ & $\begin{array}{c}31(49.2) \\
20(31.8) \\
8(12.7) \\
0(0.0) \\
4(6.4)\end{array}$ & $\begin{aligned} 16 & (64.0) \\
3 & (12.0) \\
2 & (8.0) \\
3 & (12.0) \\
0 & (0.0)\end{aligned}$ & $\begin{array}{l}.210 \\
.057 \\
.718 \\
.021 \\
.574\end{array}$ \\
\hline
\end{tabular}

TABLE 1. Continued

\begin{tabular}{|c|c|c|c|}
\hline Variable & $\begin{array}{c}\text { Radiotherapy } \\
(\mathbf{N}=63)\end{array}$ & $\begin{array}{l}\text { Surgery } \\
(\mathbf{N}=\mathbf{2 5})\end{array}$ & $P$ \\
\hline Distant lymph node & $1(1.6)$ & $1(4.0)$ & .490 \\
\hline Peritoneum & $1(1.0)$ & $0(0.0)$ & 1.000 \\
\hline SSS & $\begin{array}{c}657.2(588.7- \\
700.1)\end{array}$ & $\begin{array}{c}728.7(696.7- \\
748.7)\end{array}$ & $<.001$ \\
\hline Systemic therapy & & & .259 \\
\hline None & $5(7.9)$ & $5(20.0)$ & \\
\hline Platinum doublet & $44(69.8)$ & $15(60.0)$ & \\
\hline $\begin{array}{l}\text { Angiogenesis inhibitor } \\
\text { or targeted therapy }\end{array}$ & $14(22.2)$ & $5(20.0)$ & \\
\hline Date of diagnosis & & & .237 \\
\hline $2000-2012$ & $29(46.0)$ & $15(60.0)$ & \\
\hline 2013-2017 & $34(54.0)$ & $10(40.0)$ & \\
\hline
\end{tabular}

All data are presented as $\mathrm{N}(\%)$ or median (IQR), unless otherwise specified. $N H W$, Non-Hispanic white; $N H B$, non-Hispanic black; $E C O G$, Eastern Cooperative Oncology Group; $P S$, performance status; $I Q R$, interquartile range; SSS, Surgical Selection Score.

similar proportion received systemic therapy before any LCT (radiotherapy: 37/58, 63.8\%; surgery: $9 / 20,45.0 \%$; $P=.141)$. Patients who underwent pulmonary resection as $\mathrm{LCT}_{\text {Primary }}$ more frequently underwent resection of metastatic lesions alone or in combination with radiotherapy $(16 / 25,60.0 \%)$ than those who underwent radiotherapy as $\mathrm{LCT}_{\text {Primary }}(8 / 63,12 / 7 \% ; P<.001)$; the remainder of patients underwent radiotherapy alone as treatment of their metastatic disease. No patient received an immune checkpoint inhibitor (ICI). There was no difference in the duration between diagnosis and $\mathrm{LCT}_{\text {Primary }}$ (radiotherapy: median, 4.4 months, IQR, 2.5-6.0 months; surgery: 3.7 months, IQR, 1.8-4.4 months; $P=.107$ ). Median post-LCT $\mathrm{L}_{\text {Primary }}$ follow-up duration was similar between groups (radiotherapy: 61.5 months, 95\% confidence interval [CI], 25.9-90.7 months; surgery: 57.2 months, 95\% CI, 44.9-76.8 months; $P=.715$ ).

\section{Treatment Characteristics and Survival Outcomes After LCT Primary $_{\text {}}$}

Of the 25 patients who underwent surgery, $20(80.0 \%)$ underwent lobectomy, $2(8.0 \%)$ underwent sublobar resection, and $3(12.0 \%)$ underwent pneumonectomy. Formal lymphadenectomy was performed in $96.0 \%$ (24/25) of patients who underwent resection (median number of lymph nodes harvested 14.0; interquartile range, 10.5-17.5). Of the 63 patients who received radiotherapy as $\mathrm{LCT}_{\text {Primary }}$, most underwent conventionally fractionated external beam radiotherapy $(51 / 63,81.0 \%)$, and stereotactic body radiotherapy (SBRT) was less frequently used $(9 / 63$, $14.3 \%$; radiotherapy fractionation details unavailable for $3 / 63,4.8 \%)$. Nodal upstaging was identified in 7 patients after surgery $(7 / 25,28.0 \%$; $4 / 7$ were upstaged from cN0 to $\mathrm{pN} 1,2 / 7 \mathrm{cN} 0$ to $\mathrm{pN} 2,1 / 7 \mathrm{cN} 1$ to $\mathrm{pN} 2$ ). There were no 


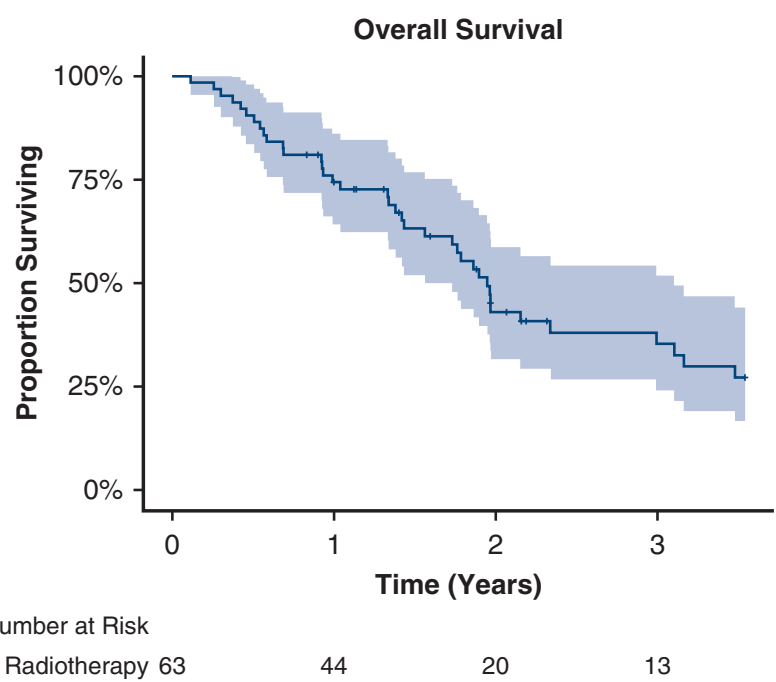

IGURE 2. Kaplan-Meier OS estimates of post-treatment OS among patients who underwent radiotherapy as LCT for the primary tumor $(\mathrm{N}=63)$.

30-day mortalities in either cohort, and rates of 90-day mortality were low (radiotherapy: $1 / 63,1.6 \%$; surgery: $0 / 25$, $0.0 \% ; P=1.000)$.

Median OS time among the entire cohort was 27.7 months (95\% CI, 21.1-42.7 months). Rates of 1-, 3-, and 5-year OS after radiotherapy were $74.3 \%$ (95\% CI, 61.6-83.4), 35.3\% (95\% CI, 22.2-48.7), and 24.2\% (95\% CI, 12.6-37.8). Median OS time after radiotherapy was 23.4 months $(95 \% \mathrm{CI}$, 17.2-35.9 months, Figure 2). After pulmonary resection, rates of 1-, 3-, and 5-year OS were 95.7\% (95\% CI, 72.999.4), 68.2\% (95\% CI, 44.5-83.4), and 48.0\% (95\% CI, 23.4-69.0), respectively. After surgery, median postoperative survival time was 55.2 months $(95 \%$ CI, 20.1 months to not reached, Figure 3 ). We next performed exploratory stratified analyses of the cohort according to the median observed SSS. Among patients with high (greater than median) SSS, Median OS time after radiotherapy was 23.6 months (95\% CI, 12.0-41.8 months), with 1-, 3-, and 5 -year OS of $82.6 \%, 40.8 \%$, and $23.3 \%$, respectively (Figure E1). After surgery, median OS time was 55.2 months (95\% CI, 27.7 months to not reached); 1-, 3-, and 5-year OS were $95.0 \%, 73.7 \%$, and $49.3 \%$, respectively (Figure E2).

\section{Patterns of Treatment Failure After LCT Primary $_{\text {}}$}

Of 63 patients who underwent radiotherapy as $\mathrm{LCT}_{\text {Primary, }}$ $10(15.9 \%)$ had locoregional progression at the time of first treatment failure. One- and 3-year freedom from locoregional progression were 87.7\% (95\% CI, 79.6-96.7) and 76.9\% (95\% CI, 63.1-93.8), respectively, after radiotherapy to the primary tumor. Progression at a treated oligometastatic site was similarly uncommon $(12 / 63,19.1 \%)$, and development of new systemic metastases was the most frequently observed pattern of progression $(33 / 63,52.4 \%)$. One- and 3 -year freedom from systemic progression were $60.0 \%$

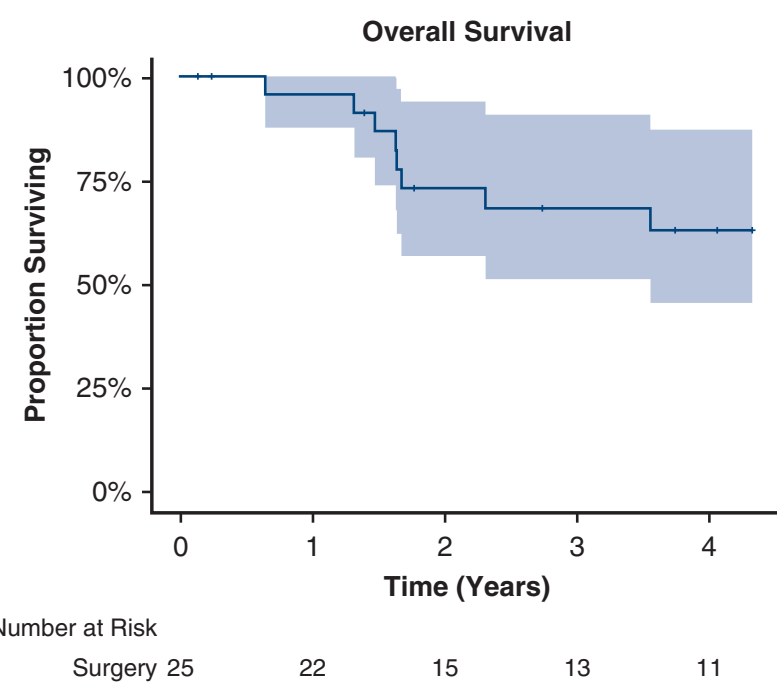

FIGURE 3. Kaplan-Meier OS estimates of post-treatment OS among patients who underwent pulmonary resection as LCT for the primary tumor $(\mathrm{N}=25)$.

(95\% CI, 49.0-74.0) and 40.2\% (95\% CI, 26.5-60.9), respectively.

Locoregional treatment failure was uncommon after pulmonary resection $(3 / 25,12.0 \%)$, with estimated $1-$ and 3 -year freedom from locoregional progression of $91.1 \%$ (95\% CI, 79.6-96.7) and 86.5\% (95\% CI, 73.5-100). Six patients $(6 / 25,24.0 \%)$ had progression at a known oligometastatic site after pulmonary resection and $12(48.0 \%)$ developed new systemic metastases. Rates of 1 - and 3 -year postoperative freedom from systemic progression were $61.1 \%(95 \% \mathrm{CI}, 44.1-84.6)$ and $41.4 \%(95 \% \mathrm{CI}$, 23.4-73.1). Intriguingly, no differences in locoregional or systemic progression were observed between the 2 groups among the entire study cohort (Figure $4, A$ and $B$ ). To account for differential survival between the 2 cohorts, we analyzed locoregional and systemic progression with death as a competing risk. No difference was observed between the 2 groups in the cumulative incidence of locoregional $(P=.635)$ or systemic progression $(P=.747)$. Exploratory stratified analysis of patients with high (greater than median) SSS demonstrated similar results, with no observed differences in freedom from locoregional progression (Figure E3A), freedom from systemic progression (Figure E3B), or upon competing risks analysis of the cumulative incidence of locoregional $(P=.256)$ and systemic $(P=.626)$ progression. No differences were observed in rates of use of second-line systemic therapy after progres-

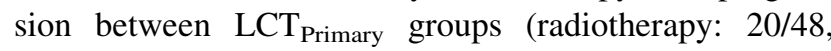
$41.7 \%$; pulmonary resection: $10 / 18,55.6 \% ; P=.313)$.

\section{DISCUSSION}

In this retrospective analysis of patients with oligometastatic NSCLC who received comprehensive LCT, a selected 

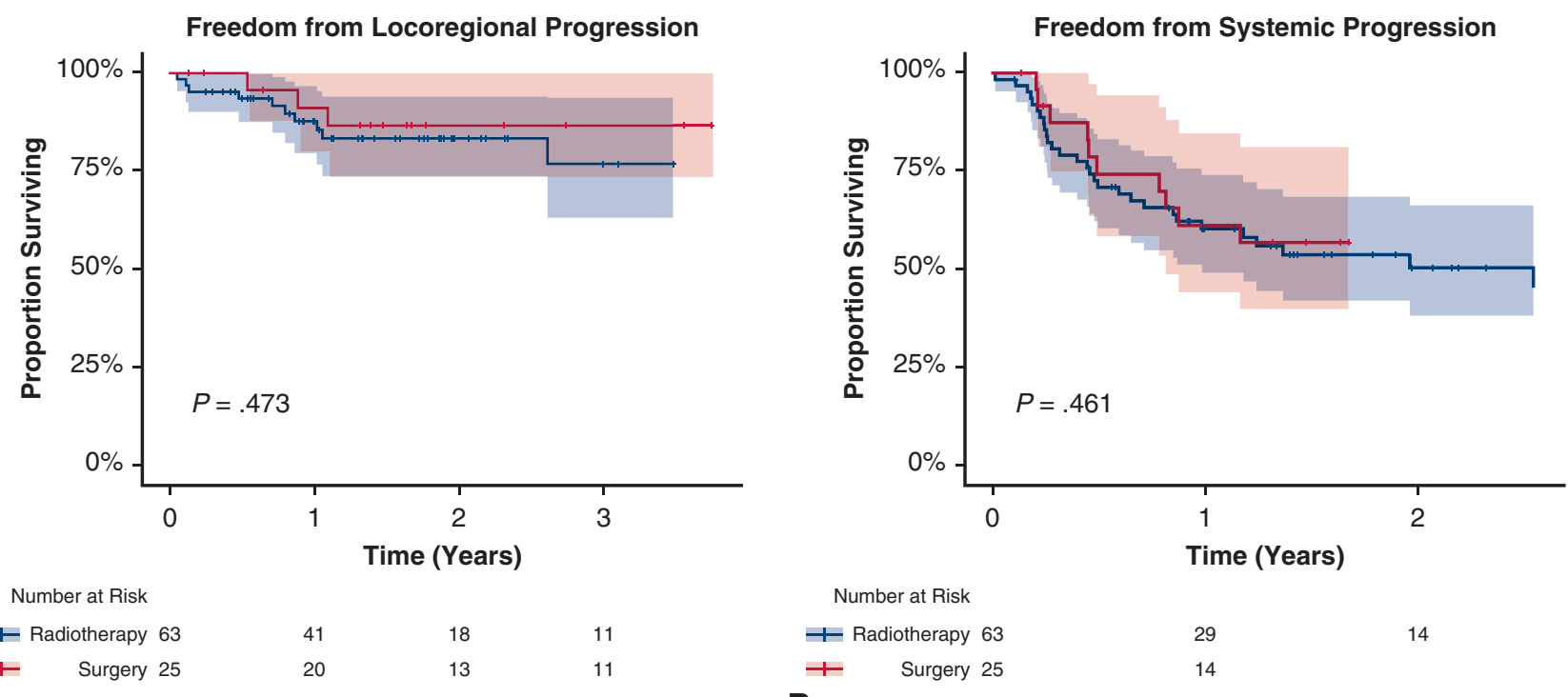

A

FIGURE 4. Kaplan-Meier estimates of freedom from progression according to therapeutic modality (pulmonary resection or radiotherapy) used as LCT for the primary tumor $(\mathrm{N}=88)$. A, Freedom from locoregional progression. B, Freedom from systemic progression.

subset of patients who underwent resection of their primary tumor experienced durable postoperative survival that was at least comparable to a benchmark group of patients who received radiotherapy. Both modalities were associated with low immediate post-treatment mortality and with rates of five-year OS that surpass those expected for patients with metastatic disease. ${ }^{1,14}$ These results suggest that, among well-selected patients, pursuit of maximal locoregional control via surgical resection is feasible and reasonable when able to be performed with a low risk of postoperative mortality. Although we caution against direct comparisons between the 2 modalities based on the data presented here, we submit that these findings highlight that pulmonary resection and radiotherapy should both remain therapeutic options for oligometastatic NSCLC patients enrolled in ongoing and future clinical trials.

The approach to management of oligometastatic NSCLC is rapidly evolving. Retrospective data that suggested improved outcomes after LCT in this setting ${ }^{7,15,16}$ have been recently supported by several phase II trials that reported improved survival and delayed development of new systemic metastases among patients treated with comprehensive LCT., ${ }^{2,3}$ However, identification of patient subgroups most likely to derive a therapeutic benefit from aggressive local consolidation remains challenging. The lack of prospective studies with adequate power to detect subgroup-specific effects has resulted in several retrospective attempts at delineation of the best candidates for comprehensive LCT. ${ }^{15,16}$ Among other stratification tools, a composite risk assessment index has been developed from analyses of the National Cancer Database and was identified as having prognostic significance among patients with advanced NSCLC. ${ }^{11,12}$ Phase III data will be critical to characterize the relative merits of each local therapeutic modality, as well as to identify which clinical, pathologic, and genomic characteristics may be used to define patient subgroups that warrant the most aggressive management approach.

As systemic control in patients with oligometastatic NSCLC continues to improve with the use of contemporary targeted agents and ICIs, ${ }^{17}$ we speculate that optimization of locoregional control will become increasingly clinically relevant. As a consequence, the optimal sequence and modality of therapies used to control the primary tumor constitutes an urgent clinical question. Surgical therapy in patients medically fit to undergo resection allows the opportunity for salvage radiotherapy in the event of a locoregional recurrence, whereas salvage resection after radiation may be a more complex clinical undertaking. ${ }^{18}$ Early clinical experience with resection after neoadjuvant ICIs or targeted therapies is accruing, ${ }^{19}$ and the technical difficulty of resection may be increased after preoperative administration of these agents. However, use of enhanced recovery pathways may mitigate perioperative morbidity despite potentially increased rates of conversion to open resection as operative indications expand. ${ }^{20}$ Further complicating this question, the potential for maximizing locoregional control by resecting the primary tumor and mediastinal nodes must be weighed against the theoretical benefits of immune priming and abscopal effects after radiotherapy, particularly in light of data demonstrating improved response to ICIs after external radiation. ${ }^{21-23}$ The most frequent pattern of progression in both cohorts in this study was overwhelmingly the development of new systemic 
metastases, with low observed rates of isolated locoregional failure in both groups. As such, the data presented are insufficient to determine differences in locoregional control between radiotherapy and pulmonary resection. Pending additional data from randomized trials, these questions regarding the optimal sequence and modality of local therapies for the primary tumor and metastatic lesions unfortunately remain unanswered.

\section{Study Limitations}

A key limitation of the present study is its retrospective nature, the highly selected nature of the patients who underwent treatment with comprehensive LCT, and the difficulty in retrospectively identifying the true intention-to-treat among patients who did not receive comprehensive LCT. Although we attempted to limit the impact of selection biases on the 2 exposure groups included (ie, those who underwent pulmonary resection and those who underwent radiotherapy as $\mathrm{LCT}_{\text {Primary }}$ ) by careful definition of inclusion criteria, ${ }^{11,12}$ to what extent the patients who were treated with radiotherapy would have been deemed medically operable cannot be definitively ascertained. In fact, despite these careful selection criteria, we noted differences between the 2 groups in terms of several clinical and pathologic characteristics. As such, the presence of measured confounders, as well as the likelihood of unquantifiable confounding factors, limited direct comparisons between radiotherapy and surgical therapy as $\mathrm{LCT}_{\text {Primary }}$ modalities. We deliberately did not perform direct OS comparisons between the 2 groups, because to do so would provide clinically uninterpretable results. Noting these limitations, we nonetheless elected to analyze OS as the primary outcome in this work because it is a clearly defined and objective end point, is relevant to ongoing research as the primary end point of several ongoing trials (eg, NCT03391869, NCT03137771) and has been reported in analyses of prospective $^{2}$ and retrospective ${ }^{24}$ oligometastatic NSCLC cohorts. Moreover, additional analyses of prospectively enrolled cohorts will be needed to examine rigorously whether the toxicity profile of a particular therapeutic modality outweighs the possible benefit associated with its use. In addition, we defined our radiotherapy cohort according to a minimum BED that is congruent with clinical practice patterns at our institution, and whether a particular dose threshold is associated with improved locoregional control or survival requires further investigation. Because of the historical nature of this cohort, no patient received an ICI as first-line systemic therapy, and extrapolation of these results to patients treated with contemporary systemic agents is difficult. Furthermore, although the use of the SSS allowed for exploratory stratification of the cohort according to a previously published composite risk index, further validation of the SSS and development of novel prognostic tools that may be used in patients with oligometastatic
NSCLC are needed. Finally, although definition of the study cohort was made possible by the use of algorithmic methods of searching unstructured data fields within medical records, the natural language processing search might have excluded patients who would have warranted inclusion. However, despite these limitations, data in the literature regarding comparative outcomes after surgery and radiotherapy as $\mathrm{LCT}_{\text {Primary }}$ in oligometastatic NSCLC are sparse, and the present study constitutes an urgently needed analysis of a question that is increasingly clinically relevant.

\section{CONCLUSIONS}

Resection of the primary tumor as a component of a comprehensive LCT management strategy was associated with long-term OS in a selected subset of patients with NSCLC presenting with synchronous oligometastatic disease. Considered in the context of the outcomes of a cohort who underwent radiotherapy as local therapy for their primary lesion, the results of the present study support the use of pulmonary resection as a therapeutic option in well-selected patients in this setting. As phase III trials of LCT in oligometastatic NSCLC continue to be designed and implemented, we ask that the lung cancer community at large insist on reserving pulmonary resection as a local therapeutic option for appropriately selected patients.

\section{Webcast}

You can watch a Webcast of this AATS meeting presentation by going to: https://aats.blob.core.windows.net/media/ ITSOS19/Resized \% 20Vidoes/new\% 20oct\% 2029/ITSOS 2019_092819_Pulmonary\%20Resection\%20is\%20Ass ociated $\% 20$ with $\% 20$ Durable $\% 20$ Overall $\% 20$ Survival $\%$ 20 in $\% 20$ Sychronous $\% 20$ Oligometastic $\% 20$ Non-Small $\%$ 20Cell\%20Lung \%20Cancer_Kyle\%20G.\%20Mitchell\% 2C\%20MD.mp4.

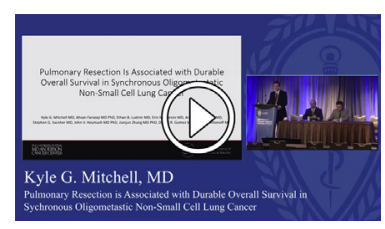

\section{Conflict of Interest Statement}

Dr Swisher has participated in advisory committees for Ethicon and for the Peter MacCallum Cancer Center. Dr Heymach has received research support from AstraZeneca, Bayer, GlaxoSmithKline, and Spectrum; participated in advisory committees for AstraZeneca, Boehringer Ingelheim, Exelixis, Genentech, GlaxoSmithKline, Guardant Health, Hengrui, Lilly, Novartis, Specrtum, EMD Serono, and Synta; and received royalties and/or licensing fees from Spectrum. Zhang served on advisory board for AstraZeneca and Geneplus and received speaker's fees from 
BMS, Geneplus, OrigMed, Innovent, grant from Merck, outside the submitted work. Dr Gomez: Varian, Merck, BMS, AstraZeneca, Reflexion, Vindico, Medscape. All other authors have nothing to disclose with regard to commercial support.

The authors thank Jeff Jin and Sam Camp with the natural language processing search.

\section{References}

1. SEER stat fact sheets: lung and bronchus cancer. Surveillance, Epidemiology, and End Results program cancer statistics. Available at: https://seer.cancer.gov/ statfacts/html/lungb.html. Accessed August 19, 2019.

2. Gomez DR, Tang C, Zhang J, Blumenschein GR Jr, Hernandez M, Lee JJ, et al. Local consolidative therapy vs. maintenance therapy or observation for patients with oligometastatic non-small-cell lung cancer: long-term results of a multiinstitutional, phase ii, randomized study. J Clin Oncol. 2019;37:1558-65.

3. Iyengar P, Wardak Z, Gerber DE, Tumati V, Ahn C, Hughes RS, et al. Consolidative radiotherapy for limited metastatic non-small cell lung cancer: a phase 2 randomized clinical trial. JAMA Oncol. 2018;4:e173501.

4. Palma DA, Olson R, Harrow S, Gaede S, Louie AV, Haasbeek C, et al. Stereotactic ablative radiotherapy versus standard of care palliative treatment in patients with oligometastatic cancers (SABR-COMET): a randomised, phase 2, openlabel trial. Lancet. 2019;393:2051-8.

5. Elamin YY, Antonoff M, Blakely C, Baggstorm M, Bivona T, Le X, et al. Randomized phase II trial of osimertinib with or without local consolidation therapy (LCT) for patients with EGFR-mutant metastatic NSCLC (NORTHSTAR). Ann Oncol. 2018;29:1509TiP.

6. Mitchell KG, Farooqi A, Ludmir B, Corsini EM, Zhang J, Zepesi B, et al. Improved overall survival with comprehensive local consolidative therapy in synchronous oligometastatic non-small cell lung cancer. Clin Lung Cancer. 2019;21:37-46.e7.

7. Sheu T, Heymach JV, Swisher SG, Rao G, Weinberg JS, Mehran R, et al. Propensity score-matched analysis of comprehensive local therapy for oligometastatic non-small cell lung cancer that did not progress after front-line chemotherapy. Int J Radiat Oncol Biol Phys. 2014;90:850-7.

8. Martini N, Melamed MR. Multiple primary lung cancers. J Thorac Cardiovasc Surg. 1975;70:606-12.

9. National Comprehensive Cancer Network. NCCN clinical practice guidelines in oncology: non-small cell lung cancer, version 3.2019. Available at: http://www nccn.org/professionals/physician_gls/default.aspx. Accessed February 6, 2020.

10. Amin MB, Edge S, Greene F, Byrd DR, Brookland RK, Washington MK, et al. AJCC Cancer Staging Manual. 8th ed. New York, NY: Springer; 2017.

11. David EA, Andersen SW, Beckett LA, Melnikow J, Clark JM, Brown LM, et al. Survival benefits associated with surgery for advanced non-small cell lung cancer. J Thorac Cardiovasc Surg. 2019;157:1620-8.
12. David EA, Andersen SW, Beckett LA, Melnikow J, Kelly K, Cooke DT, et al. A model to predict the use of surgical resection for advanced-stage non-small cell lung cancer patients. Ann Thorac Surg. 2017; 104:1665-72.

13. Shuster JJ. Median follow-up in clinical trials. J Clin Oncol. 1991;9:191-2.

14. Chansky K, Nicholson AG, Rusch VW, Vallieres E, Groome P, Kennedy C, et al. The IASLC Lung Cancer Staging Project: external validation of the revision of the TNM stage groupings in the eighth edition of the TNM classification of lung cancer. J Thorac Oncol. 2017;12:1109-21.

15. Ashworth AB, Senan S, Palma DA, Riquet M, Ahn YC, Ricardi U, et al. An individual patient data metaanalysis of outcomes and prognostic factors after treatment of oligometastatic non-small cell lung cancer. Clin Lung Cancer. 2014;15: 346-55.

16. Li D, Zhu X, Wang H, Qiu M, Li N. Should aggressive thoracic therapy be performed in patients with synchronous oligometastatic non-small cell lung cancer? A meta-analysis. J Thorac Dis. 2017;9:310-7.

17. Doroshow DB, Sanmamed MF, Hastings K, Politi K, Rimm DL, Chen L, et al. Immunotherapy in non-small cell lung cancer: facts and hopes. Clin Cancer Res. 2019;25:4592-602.

18. Antonoff MB, Correa AM, Sepesi B, Nguyen QN, Walsh GL, Swisher SG, et al. Salvage pulmonary resection after stereotactic body radiotherapy: a feasible and safe option for local failure in selected patients. J Thorac Cardiovasc Surg. 2017; 154:689-99.

19. Bott MJ, Yang SC, Park BJ, Adusumilli PS, Rusch VW, Isbell JM, et al. Initial results of pulmonary resection after neoadjuvant nivolumab in patients with resectable non-small cell lung cancer. J Thorac Cardiovasc Surg. 2019;158: 269-76.

20. Van Haren RM, Mehran RJ, Mena GE, Correa AM, Antonoff MB, Baker CM, et al. Enhanced recovery decreases pulmonary and cardiac complications after thoracotomy for lung cancer. Ann Thorac Surg. 2018;106:272-9.

21. Niknam S, Barsoumian HB, Schoenhals JE, Jaskon HL, Yanamandra N, Caetano MS, et al. Radiation followed by OX40 stimulation drives local and abscopal antitumor effects in an anti-PD1-resistant lung tumor model. Clin Cancer Res. 2018;24:5735-43.

22. Ngwa W, Irabor OC, Schoenfeld JD, Hesser J, Demaria S, Formenti SC Using immunotherapy to boost the abscopal effect. Nat Rev Cancer. 2018;18 313-22.

23. Twyman-Saint Victor C, Rech AJ, Maity A, Rengan R, Pauken KE, Stelekati E, et al. Radiation and dual checkpoint blockade activate non-redundant immune mechanisms in cancer. Nature. 2015;520:373-7.

24. Xu Q, Zhou F, Liu H, Jiang T, Li X, Xu Y, et al. Consolidative local ablative therapy improves the survival of patients with synchronous oligometastatic NSCLC harboring EGFR activating mutation treated with first-line EGFR-TKIs. J Thorac Oncol. 2018;13:1383-92.

Key Words: local consolidative therapy, non-small cell lung cancer, oligometastatic, radiotherapy, surgical therapy 


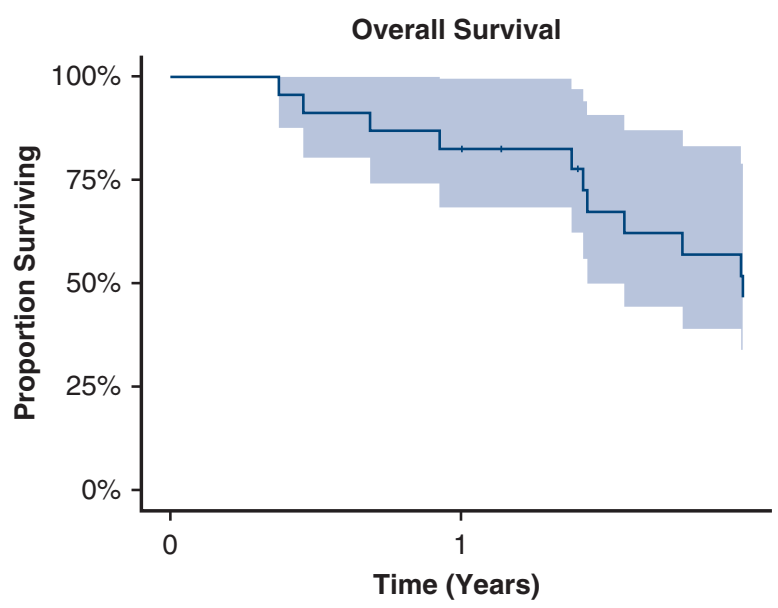

Number at Risk
Radiotherapy 23

19

FIGURE E1. Kaplan-Meier OS of post-treatment OS among patients with SSS greater than the observed median for the entire cohort who underwent radiotherapy as LCT for the primary tumor $(\mathrm{N}=23)$.

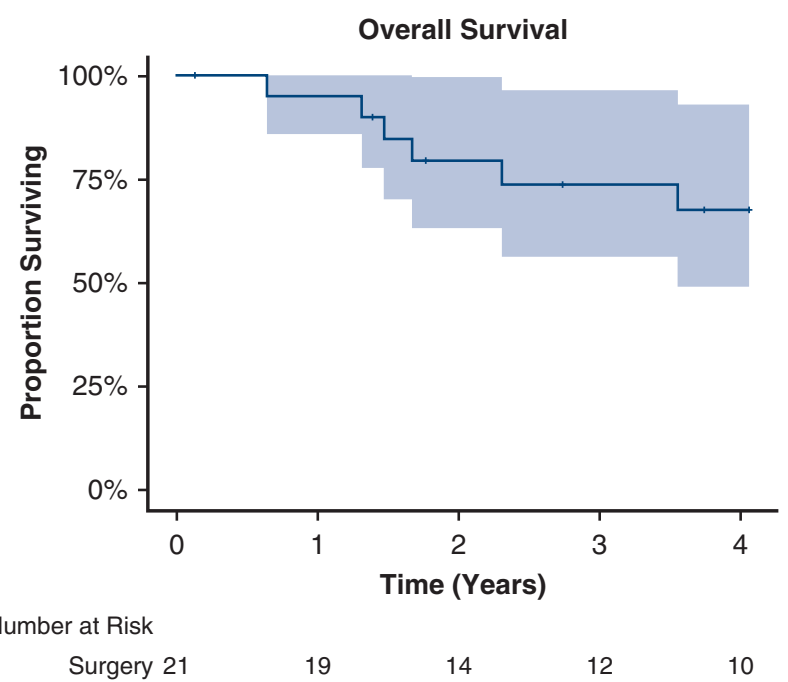

FIGURE E2. Kaplan-Meier OS of post-treatment OS among patients with SSS greater than the observed median for the entire cohort who underwent pulmonary resection as LCT for the primary tumor $(\mathrm{N}=21)$. 
Freedom from Locoregional Progression

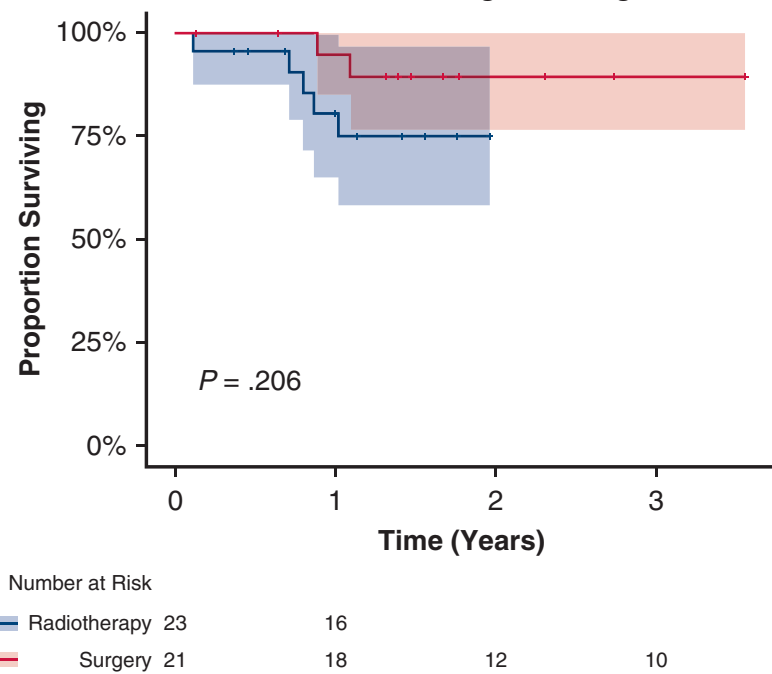

A

FIGURE E3. Kaplan-Meier estimates of freedom from progression according to therapeutic modality employed as LCT for the primary tumor among patients with SSS greater than the observed median for the entire cohort $(\mathrm{N}=44)$. A, Freedom from locoregional progression. B, Freedom from systemic progression.

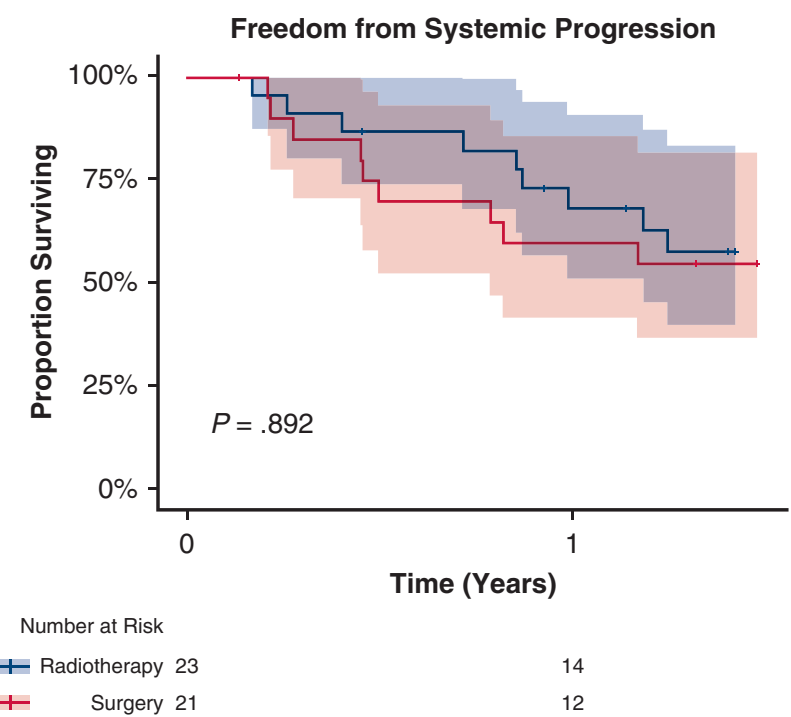

$+\quad$ Surgery 21

12 